\title{
Natural killer cells in patients with severe chronic fatigue syndrome
}

\author{
E. W. Brenu - S. L. Hardcastle - G. M. Atkinson • \\ M. L. van Driel · S. Kreijkamp-Kaspers • \\ K. J. Ashton · D. R. Staines · S. M. Marshall-Gradisnik
}

Received: 28 November 2012/ Accepted: 6 March 2013/Published online: 16 April 2013

(C) Springer-Verlag Italia 2013

\begin{abstract}
Maintenance of health and physiological homeostasis is a synergistic process involving tight regulation of proteins, transcription factors and other molecular processes. The immune system consists of innate and adaptive immune cells that are required to sustain immunity. The presence of pathogens and tumour cells activates innate immune cells, in particular Natural Killer (NK) cells. Stochastic expression of NK receptors activates either inhibitory or activating signals and results in cytokine production and activation of pathways that result in apoptosis of target cells. Thus, NK cells are a necessary component of the immunological process and aberrations in their functional processes,
\end{abstract}

Electronic supplementary material The online version of this article (doi:10.1007/s13317-013-0051-x) contains supplementary material, which is available to authorized users.

E. W. Brenu · S. L. Hardcastle · G. M. Atkinson ·

S. M. Marshall-Gradisnik

Griffith Health Institute, School of Medical Science, Griffith

University, Gold Coast, QLD, Australia

E. W. Brenu - S. L. Hardcastle - G. M. Atkinson ·

D. R. Staines - S. M. Marshall-Gradisnik

The National Centre for Neuroimmunology and Emerging

Diseases, Griffith University, Gold Coast, QLD, Australia

E. W. Brenu $(\bowtie)$

Immunology Research Group, Centre for Medicine and Oral

Health, Griffith University, GH1, Room 7.59, Southport, QLD

4215, Australia

e-mail: e.brenu@griffith.edu.au

M. L. van Driel · D. R. Staines

Queensland Health, Gold Coast Public Health Unit, Robina, Gold Coast, QLD, Australia

S. Kreijkamp-Kaspers · K. J. Ashton Faculty of Health Sciences and Medicine, Bond University, Robina, QLD, Australia including equivocal levels of NK cells and cytotoxic activity pre-empts recurrent viral infections, autoimmune diseases and altered inflammatory responses. NK cells are implicated in a number of diseases including chronic fatigue syndrome (CFS). The purpose of this review is to highlight the different profiles of NK cells reported in CFS patients and to determine the extent of NK immune dysfunction in subtypes of CFS patients based on severity in symptoms.

Keywords Chronic fatigue syndrome $\cdot$ Natural killer cells $\cdot$ Cytotoxicity $\cdot$ Perforin · Granzymes

\section{Introduction}

Natural killer (NK) cells are granular lymphocytes originating from the CD34 hematopoietic progenitor cell lineage and are found in the peripheral blood, spleen, bone marrow and lymph nodes. The composition of NK cells in comparison to the total lymphocyte population is about $15 \%$ [1]. These cells are important in the principal innate immune defence in response to pathogen invasion following recognition. NK cells are imperative during viral and microbial infection and tumour development, aiding in the body's immunity through cytokine secretion and cytotoxic activity, which induces apoptosis in target cells. Thus, NK cells are vital for pathogen clearance prior to the adaptive immune response. Aberrant production of cytokines and induction of cytotoxic activity are related to a number of disease presentations such as rheumatoid arthritis [2], chronic obstructive pulmonary disorder [3], neurological conditions including Alzheimer's and multiple sclerosis [4, 5] and cancers [6-9]. In particular, NK cell cytotoxic dysfunction has been associated with chronic fatigue syndrome (CFS). 
Subsets of NK cells

Natural killer cells can be grouped into two types, however, further classifications generates at least five subsets of NK cells $[10,11]$. These cells are mainly grouped according to the presence of the Fc gamma receptor III (CD16) and the neural cell adhesion molecule (CD56). The density of these markers on the NK cells defines the classification of different subsets of NK cells. Thus, NK cells can be grouped into $\mathrm{CD} 56^{\text {bright }} \mathrm{CD} 16^{\mathrm{dim}}, \mathrm{CD} 56^{\text {bright }} \mathrm{CD} 16^{-}, \mathrm{CD} 56^{-} \mathrm{CD} 16^{\text {bright }}$, $\mathrm{CD} 56^{\mathrm{dim}} \mathrm{CD} 16^{\text {bright }}$ and $\mathrm{CD} 56^{\mathrm{dim}} \mathrm{CD} 16^{-} \mathrm{NK}$ cells $[10,11]$. About $90 \%$ of the NK cells in the periphery are CD56 ${ }^{\mathrm{dim}} \mathrm{CD} 16^{\text {bright }}$ while $10 \%$ express CD56 ${ }^{\text {bright }}$ on their cell surfaces [10]. NK cells with a high density of the CD16 molecules are considered highly cytotoxic and secrete low levels of cytokines while those densely populated with CD56 markers are the dominant producers of NK-related cytokines and are less cytotoxic [10]. The cytokines secreted by these NK cells include granulocyte macrophage colony-stimulating factor (GMC-SF), IFN- $\gamma$, TNF- $\alpha$, IL-10 and IL-13. The ability to induce cytotoxic activity and produce cytokines is vital for sustained physiological homeostasis.

NK cell receptors

Natural killer cells express a number of activating and inhibitory receptors generated from genes with variable or conserved sequences. The most variable and polymorphic NK receptors are the killer cell immunoglobin-like receptor (KIR) family of receptors while the others such as NKG2D are highly conserved [12]. KIRs are a family of inhibitory receptors that reside as transmembrane proteins, with two or more extracytoplasmic immunoglobin-like domains with either short or long cytoplasmic tails that have an immunoreceptor tyrosine-based activation or inhibition motif (ITAM and ITIM, respectively). KIRs contain a long cytoplasmic tail and do not associate with adaptor molecules. The activation of KIRs is dependent upon the recognition of MHC class I molecules. The primary function of these receptors is the inhibition of cytotoxic activitythe inhibitory KIRs are associated with having a longer cytoplasmic tail. However, some KIRs containing ITAM motif, KIR2DS/3DS, are known to stimulate cytotoxic activity [13].

Natural killer cells undergo cytotoxic activation by exogenous activation of surface receptors. Activating NK receptors including, NKp46, NKp30 and NKp44, all share the association of a signalling peptide existing on cytoplasmic tail, known as ITAM. ITAMs are highly conserved peptides containing tyrosine residues [14]. The ITAM peptide is a crucial intermediate between activation of the surface receptor and downstream effector signalling, which in the case of NK cell is cytotoxic activation and the production of cytokines including IFN- $\gamma$, tumour necrosis factor $\beta$ (TNF- $\beta$ ), IL-10 and IL-13. The activation receptors of NK cells have a broad specificity and can be activated by target cell antibody interaction, such as that of an antigen presenting cell or B cell, or through the recognition of the MHC class I-like complex. It has been indicated that numerous receptor activation and cross linking between these receptors is required for NK cytotoxic activation [15].

Natural killer cell activation predominantly relies on receptors. Upon recognition of the adaptor molecule, the ITAM components of the receptor are activated through the phosphorylation of its tyrosine residues [14]. This temporary binding site now has an affinity to activate of ITAM, which leads to the recruitment of a src-family kinase (SH2) pathway and downstream syk/ZAP70 transcription. Syk acts through the PI3K-dependent pathway to activate Rac1, PAK1, MEK and ERK pathways increasing calcium entry, degranulation, recruitment of perforin and granzyme contained in lytic granules and cytokine gene transcription [16, 17]. These activating receptor molecules on target cells may be antibodies or MHC class 1-like molecules, requiring activation of multiple receptors and receptor cross-linking to activate cytotoxicity [18, 19]. Inhibition of NK cells occurs in the absence of a structurally sufficient MHC class I molecule, giving rise to the 'missing self' theory of cytotoxic inhibition [20]. Recognition of the target cell MHC class I, prompts ITIM phosphorylation at the tyrosine residues to recruit and activate SHP-1/2 phosphatases. SHP1/2 dephosphorylates activated ITAM pathway constituents, Syk and ZAP70, thereby inhibiting cytotoxic activation and cytokine production.

\section{NK cell cytotoxic activity}

Natural killer cells can induce apoptosis in target cells through granule-mediated and non-granule-mediated pathways. Granule-dependent cytotoxic induction is the most specialised cytotoxic function of the NK cell [21, 22]. However, the significance of non-granule-mediated pathways is evident in the diversity of lethality of the NK cell including antibody-dependent cell-mediated cytotoxicity [23-27], TRAIL and FasL death receptor pathways [2830].

The relevance of the cytolytic granule-mediated pathway to the CFS disease state is supported by a growing body of evidence highlighting cytotoxic dysfunction and the immune system [31-37], summarised by Bansal et al. [38]. By activation of the granule-mediated pathway, NK cells secrete perforin and granzymes into the target cells. Perforin is a protein that either forms pores on the plasma 
membrane of the target cells to facilitate the passage of granzymes into the target cells or fragments the host cell endosomes, which contain granzymes [21]. They may also be directly involved in cytolytic activity and once in the target cells, granzymes bind to cell organelles to activate either caspase-dependent or -independent apoptosis. These mechanisms include nuclear envelope disruption leading to DNA degradation, disruption of mitochondrial transmembrane potential and independently activates Ape1-mediated bcl-2 overexpression [39]. NK cells may also contain a memory component that assists in future invasions by the same antigen. The primary pro-apoptotic component of NK cells-granzymes, are currently categorised into five types, only three of which have directly known functionsgranzymes A, B and K [40].

Granzymes $\mathrm{A}$ and $\mathrm{K}$ have similar functions and are known to activate slow apoptosis while granzyme B is associated with the activation of rapid apoptosis [41]. Granzyme B induces a caspase-dependent mechanism of apoptosis while granzyme A is caspase independent, inducing cell death through single stranded DNA degradation, disrupting plasma membrane integrity and mitochondrial transmembrane potential [39, 42-44]. The exact mechanism of perforin is still under investigation, however, mounting evidence tends to support oligomerisation within the target cell membrane, leading to the formation pore-like structures [45, 46]. These pores are then the gateway for NK cell-derived granzymes to enter the target cell and elicit their effect. NK cell cytotoxic activity also occurs through a number of other secondary pathways including IFN- $\gamma$, TNF- $\alpha$ and Fas-ligand pathways, the dysregulation of which may be involved in the mechanism of CFS.

\section{Chronic fatigue syndrome}

Presently, an indefinable aetiology and mechanism of CFS precludes effective diagnosis posing substantial anxiety among patients and family members. CFS is a heterogeneous disorder with multi-factorial characteristics affecting physiological processes including, endocrine, neurological, immunological and metabolic processes [4754]. Substantial physical and mental weaknesses are associated with CFS including but not limited to severe disabling fatigue, interruptions in sleep, headaches, swollen lymph nodes, cognitive disturbances and muscle pain in the absence of swelling [55]. CFS is neither age- nor gender-specific, however, females are more likely to be affected than males [56-58]. CFS is an unexplained disorder with a prevalence of $0.4-1 \%$ worldwide [59]. Nonetheless prevalence of CFS varies among patients [60].
NK cells in CFS

Chronic fatigue syndrome is known to be associated with a reduction in NK lytic activity and in some cases an irregular distribution in the levels of NK subtypes. In a range of studies, NK cytotoxic activity has been measurably decreased as compared to healthy controls $[31,33,34,61-$ 64]. There is no standard definition for CFS, however, a number of criteria have been generated to assist physicians in disaffecting CFS from other known and characterised disorders [59]. Similarly, our longitudinal investigations of CFS have shown that reduced cytotoxic activity in patients with CFS is maintained during the course of the disease and does not notably fluctuate or associate with seasonal changes. Incidentally, we have recently studied a group of severely bed-ridden patients, due to the symptoms of CFS. In these individuals, we have shown that, similar to the CFS patients who have some level of mobility outside the home, these patients demonstrated a significant decrease in cytotoxic activity in their NK cells. However, in previous investigations, reductions in NK cell function have been associated with reduced levels of NK CD56 $6^{\text {bright }}$ cells [34]. A similar trend was not observed in our severe bed-ridden population and a study of the longitudinal expression of these subsets demonstrated that these cells are not consistently reduced over time or during the course of the disease [31]. This is consistent with the NK cells subset studies in the literature where consistencies in the levels of NK cells have not been observed across all studies. The heterogeneity of CFS may be associated with these findings; however, it posits that levels of NK cells may not be an appropriate marker for identifying and distinguishing CFS from the general population. The observation of reduced NK cell cytotoxicity in both mobile and bed-ridden cases of CFS is important to the current knowledge of the disease. In the severe cases of CFS, differences in the KIR receptors may be associated with the disease presentation. Notably the transcriptional levels of some KIRs are significantly decreased in the CFS patients compared to the controls while the expression of KIR2DS5 is not observed in all CFS patients [65].

Allotypic and haplotypic differences in the expression of these KIRS may affect the induction of cytotoxic activity $[66,67]$. Due to the high polymorphic nature of KIR, it is proposed that specific polymorphisms may be associated with the differences in expression of CFS patients [68]either due to a pre-transcriptional or a compensatory means. However, studies are yet to provide details on such genomic data of KIRs in CFS patients, which may be further complicated by the heterogeneity and ambiguity of the disease presentation and symptoms. In the absence of appropriate diagnostic tools and a well-characterised suite of biomarkers, CFS remains complex. A unifying theme in 
the literature is the presence of dysfunctional immune cells specifically NK cells. Most immunological studies in CFS are concerned with the cytotoxic activity and phenotypic distribution of these cells.

\section{Equivocal levels of NK cells and phenotypes in CFS}

Chronic fatigue syndrome studies associated with peripheral NK cell phenotypes or subsets are contradictory. Studies have reported increases, decreases and no change in peripheral distribution of $\mathrm{NK}$ cell phenotypes and overall NK cells in comparison to non-fatigued participants. Regardless of these inconsistencies, alterations in NK phenotypes have adverse consequences on immune function owing to the cytokine secretion and cytolytic properties of these cells. Characterisation of NK cells into CD56 $6^{\text {bright }}$ and $\mathrm{CD}^{2} 6^{\mathrm{dim}}$ permits the determination of the distribution of cytokine producing and cytotoxic NK cells.

Overall NK cell numbers may be increased or decreased in some CFS patients $[69,70]$. Similarly, CD56 ${ }^{\text {bright }}$ NK cells may be increased or decreased in some CFS patients $[34,70]$. The consequence of equivocal levels of CD56 ${ }^{\text {bright }}$ NK cells in CFS patients is unknown. Nonetheless, CD56 ${ }^{\text {bright }} \mathrm{NK}$ cells are highly resistant to apoptosis and therefore have in increased life span in comparison to the CD56 ${ }^{\text {dim }}$ NK cells $[71,72]$. CD56 ${ }^{\text {bright }} \mathrm{NK}$ cells in close relation to $\mathrm{T}$ cells may be increased following elevations in their numbers perpetuating autoimmune responses [73]. The presence of heightened levels of CD56 ${ }^{\text {bright }}$ NK cells may suggest the presence of inflammation in the periphery. The diversity in chemokine receptor expression on the subtypes of NK cells is related to their sites of manifestation during inflammation, hence, CD56 ${ }^{\text {bright }} \mathrm{NK}$ cells expressing CCR5 are present in inflamed areas with high incidence of RANTES and MIP- $1 \alpha$ and $\beta$ [74, 75]. These NK cells are substantially activated following from their interactions with monocytes [76]. Interestingly, reduction in the levels of CD56 $6^{\text {bright }} \mathrm{NK}$ cells is suggestive of differentiation of the CD56 $6^{\text {bright }} \mathrm{NK}$ cells into the CD56 ${ }^{\text {dim }}$ NK cells [77]. Concurrent expression of high levels of CD56 ${ }^{\text {dim }}$ NK cells and low level of CD56 $6^{\text {bright }}$ NK cells may explain this phenomenon in CFS patients [70]. In diseases like AIDS, reduction in the levels of CD56 ${ }^{\mathrm{dim}} \mathrm{NK}$ cells correlates with decreases in NK cytotoxic activity [78]. The equivocal levels of NK phenotypes limits the acceptance of this assumption in CFS patients nonetheless, it is possible to posit that in some CFS patients with marked reduction in NK phenotypes and activity a similar disease profile may be observed. The heterogeneity of CFS may confuse these findings hence, levels of NK cells may not be appropriate markers for identifying and distinguishing CFS from the general population.
NK cytotoxic activity in CFS

Although NK cell phenotypes and overall NK cell numbers in the periphery are unpredictable, consistent decreases in the cytotoxic activity occur in most CFS patients $[1,5,36$, $64,69,79-83]$. A rationale for decreases in cytotoxic activity remains to be determined, however, these may be associated with altered lytic proteins in particular perforin and granzymes [37]. Lytic proteins are important factors in the granule-dependent pathway of cytolysis. Perforin contains a membrane attack complex and a $\mathrm{C} 2$ domain that contains $\mathrm{Ca}^{2+}$ [84]. In CFS patients, perforin gene expression may be increased in conjunction with relatively low to normal levels of granzymes [32, 37, 85].

Perforin is an important indicator to cytotoxic activity as it is an absolute necessity for granule-related apoptosis [21, 86]. Incidentally, mice lacking perforin demonstrate reduced apoptosis [86, 87]. Trafficking or exportation of granzymes into the target cell is dependent on the availability of perforin thus its deficiency pre-empts decreased cytotoxic activity owing to the paucity in the available granzymes to induce apoptosis [21, 45]. Granzyme distribution in some CFS patients may be reduced [32]. It is known that during development the level of perforin in the NK cell is related to the expression of CD56. Following maturation, a substantial proportion of NK cell-related perforin is detected in the CD56 ${ }^{\mathrm{dim}} \mathrm{NK}$ cells in comparison to the CD56 ${ }^{\text {bright }} \mathrm{NK}$ cells [88]. Upregulation of perforin is regulated by important proteins including IFN- $\beta$, IL-2, IL6, IL-12, IL-15 and IL-21 [89, 90]. In CFS IL-2, IL-6, IL15 and IL-21 are known to be characterised by alterations in cytokine levels, this may be a contributory factor to the decrease in cytotoxicity [91, 92].

Granzyme decrease in CFS may be attributed to decreases in perforin although correlations remain to be proven. Granzymes are serine proteases, in humans they include, granzyme A, B, H, M and K [93-96]. Granzyme A and $\mathrm{B}$ are the most characterised and they induce apoptosis via distraction of endoplasmic reticulum SET complex or activating of caspase 3 following cleavage of substrates as previously mentioned [97]. Granzymes are found in the extracellular fluids such as plasma, cerebrospinal fluids and synovial fluid and are therefore implicated in the regulation of inflammation [98]. The diverse role of perforin and granzymes in cell death-related pathways is paramount to immune function during infections. Hence, in CFS recurring infections may occur as a consequence of aberrations in cytotoxic activity. Importantly, NK cells employ a number of other cytotoxic pathways that may require further investigations in CFS to ascertain the exact pathway(s) that have an involvement with reduced NK cytotoxic activity. 
Other factors that may affect efficient cytotoxic activity in NK cells of CFS patients may be related to cytokine production and secretion by NK cells. Cytotoxic activity may occur via IFN- $\gamma$ and TNF- $\alpha$. Therefore, changes in these cytokines in the CFS patients may also have a contributory role to the observed decreases in cytotoxic activity in these patients. Incidentally, cytokine studies in CFS although not NK cell-specific may have a role in reduced lysis [99, 100]. Importantly, in some CFS patients, significant increases in IFN- $\gamma$ and TNF- $\alpha$ may indicate induction of other cell death pathways [31]. Nonetheless, this does not reflect an increase in cytotoxic activity as reduced cytotoxic activity still persists even when these pro-inflammatory cytokines are increased [31, 32]. IFN- $\gamma$ is the most abundant cytokine secreted by NK cells, in particular CD56 $6^{\text {bright }} \mathrm{NK}$ cells. Longitudinal assessments of cytokines in CFS patients explicitly illustrate nonconformities in the presentation of cytokine production over the cause of CFS [31]. Shifts towards pro-inflammatory cytokines such as IFN- $\gamma$ and TNF- $\alpha$ may occur initially but dissipate in time. In most cases as we have observed in our CFS patients, an increase in IFN- $\gamma$ and TNF- $\alpha$ occurred in coincidence with an increase in anti-inflammatory cytokine IL-10.

\section{NK receptors in CFS}

Natural killer receptors are the least investigated NKrelated parameters in CFS. Currently, only one study has examined the relationship between NK receptor expression in CFS patients [65]. NK cells expression a varying number of activating and inhibitory receptors that may have stochastic presentations. It is possible to posit that failures in the regulation of the expression of these receptors can affect NK function during viral invasion. For example, elevated levels of inhibitory KIRs such as KIR3DL1 may result in decreased NK cell lyis in patients with lung cancer [101]. KIR receptors are exceedingly polymorphic and KIR3DL1 is no exception as it expresses eight different KIR3DL1 allotypes with differing sensitivities to antigen binding [102-105]. HIV and spondyloarthritis patients demonstrate high levels of KIR3DL1 [13, 106-108].

Similarly, the incidence of KIR3DS1 in some CFS patients exceeds that of non-fatigued controls [65]. A similar gene encodes KIR3DL1 and KIR3DS1 [109], suggesting a potential link between these receptors in CFS and cytotoxic activity. Certain ligands of these receptors may also be elevated in CFS patients [65]. Diversity in the KIR receptor polymorphism may generate receptors with differing haplotypes that are specific to CFS. Further studies are required to provide extensive details into the polymorphisms of KIRs in CFS patients, which may be further complicated by the heterogeneity and ambiguity of the disease presentation and symptoms.
NK gene expression studies in CFS

Natural killer gene expression or molecular studies in CFS are lacking, currently, only two studies have investigated mRNA and microRNA (miRNA) studies in CFS. Perhaps the lack of such studies relates to the cost associated and volume of blood required for the preferential isolation of NK cells. In PBMCs, expression of GZMA and GZMB is reduced in CFS patients in comparison to non-fatigued controls. GZMA and GZMB are genes for the protein granzyme $\mathrm{A}$ and $\mathrm{B}$, respectively. These reductions may correlate with the protein production. In our previous studies, preferential examination of lytic protein genes in CFS patients revealed a significant expression in the perforin gene PRF1 while GZMA and GZMK were significantly reduced in the CFS patients [32]. The exact cause of increase in the expression of perforin is not known, however, as perforin proteins were not measured in these CFS patients, it is difficult to predetermine an association between these PRF1 expression and perforin protein.

MicroRNAs are non-coding small RNA molecules with regulatory roles in the expression of genes including translation repression or mRNA degradation [110, 111]. In CFS, NK cell expression of miR-10a, miR-21, miR-103, miR-106, miR-146a, miR-150, miR-17-5p, miR-191 and miR-223 are down-regulated in comparison to non-fatigued controls [112]. Most of these miRNAs have been linked to a number of cancers. An association or the role of these miRNAs in NK cell-related activities is yet to be determined nonetheless these miRNAs are attributed to a number of diseases and physiological processes. Most of these miRNAs are associated with the presentation of a number of different cancers and are involved in apoptosis, cell proliferation and development. Importantly, miR-21, miR-150 are implicated in the development of lymphocytes and thus they may have similar effects in NK cells [113, 114]. Decreases in the expression of miR-10a occur in chronic myeloid leukaemia [115]. MiR-10a preserves vascular integrity by targeting HOXA1, MAP3K7 and bTRC [116]. MiR-146a upon induction has been shown to target TNF receptor-associated factor 6 (TRAF6) and the IL-1 receptor associate kinase 1 (IRAK1) genes, and these are important in the regulation of TLRs and inflammation [117]. In many cancers the presence of miR-146a resulted in cell proliferation [118]. Bacterial antigens and proinflammatory cytokines stimulate the expression of miR146a, which in turn may suppress the secretion of inflammatory cytokines [119]. Similarly, miR-21 promotes tumour growth owing to its oncogenic properties and its role in inflammation and T cell-related activities [120].

These studies on miRNAs have elucidated an important role of miRNAs in NK cells, as they regulate the expression of immune-related genes. However, these studies are 
limited as they have not identified the exact miRNA target genes in CFS patients. Such studies may be instrumental in unexplained disorders such as CFS, further research, may be required to establish these links.

\section{Implications for severe CFS patients}

The results from studies on NK cells in CFS patients suggest a potential mechanism of CFS can be identified through a thorough study of NK cell-related activities. From our observations, reductions in lytic proteins, genes and further decreases in miRNA genes [31, 34, 112], cumulatively affect efficient cytotoxic activity in CFS patients. Similarly, the polymorphic alleles of the KIR receptors may not allow efficient pathogenic and antigenic targeting of the NK cell, as an overabundance in the inhibitory KIRs may abort or impede cytotoxic activity [121]. The extent immune dysfunction in subtypes of CFS patients may differ among subgroups of patients. CFS patients may have variations in the severity of their symptoms, for example a distinct subgroup of patients maybe housebound as they suffer from high levels of fatigue and CFS-related symptoms compared to other sedentary CFS patients [122]. Their severe persistent and incapacitating symptoms probably exclude these patients from CFS-related studies. Hence, we examined for the first time NK cell-related parameters including cytotoxic activity, phenotypes and KIR receptor expression in patients with severe CFS (SCFS) in comparison to sedentary or moderate CFS (MCFS) patients and non-fatigued controls. Currently, these studies have not been performed in this group of CFS patients.

\section{NK cytotoxic activity in severe CFS patients}

Cytotoxic activity of the NK cells was measured by the ability of the cells to lyse the K562 effector cells. The NK cytotoxic activity against K562 cells was significantly decreased in the MCFS and the SCFS group $(P<0.05)$ compared to the non-fatigued control group (Fig. 1). Multiple comparison tests revealed significant decreases between the SCFS patients and the control group only. There were no significant differences between the MCFS and the control group or the SCFS and the MCFS group.

NK receptors in severe CFS patients

The percentage of NK receptor expression was determined following preferential gating on isolated NK cells in a forward and side scatter plot. This was then extrapolated on to six plots for CD56 versus the six NK receptors assessed. Significant changes in NK receptors were observed in only one receptor, KIR3DL1 (CD158e) (Fig. 2). KIR3DL1

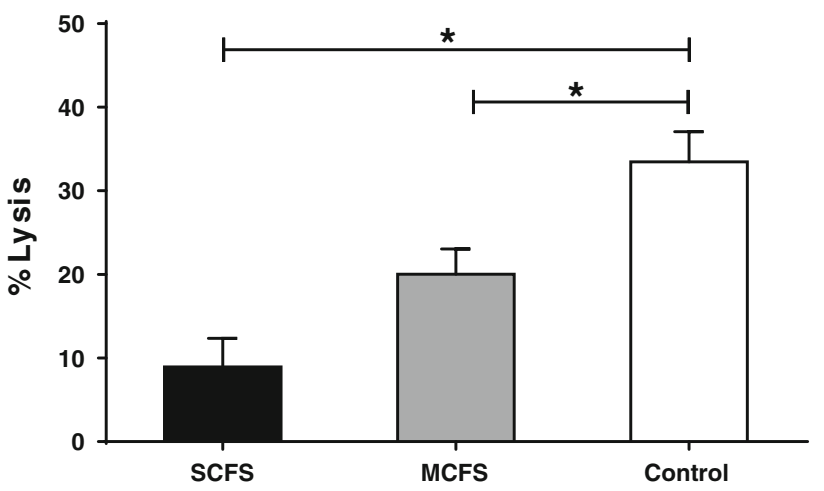

Fig. 1 Decreased NK lysis in MCFS and SCFS group compared to a non-fatigued control group. The percent lysis of NK cells in each group is represented above where the white bar represents the results from the non-fatigued control group and the black bar represents the SCFS group. Asterisk denotes statistical significance where $P<0.05$ and data is represented as the mean \pm SEM

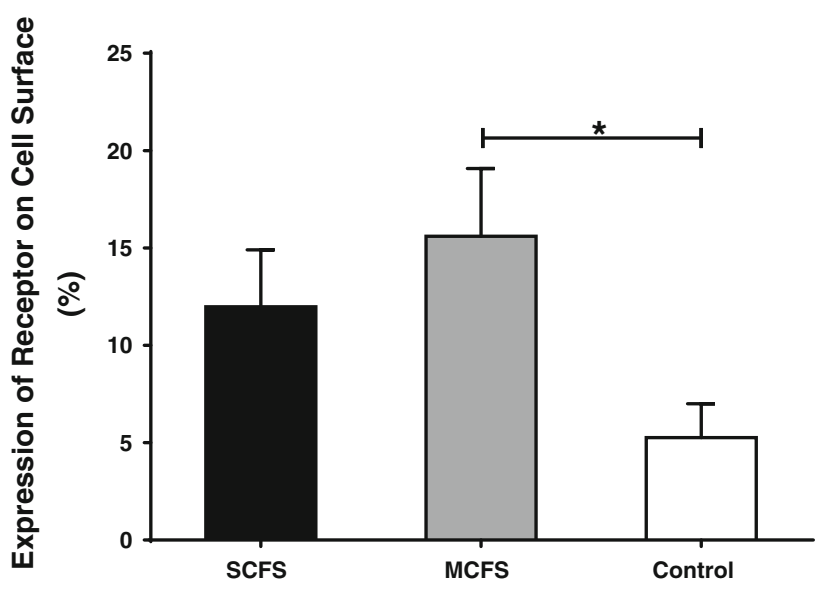

Fig. 2 Expression of KIR3DL1 in SCFS, MCFS and a non-fatigued control group. The above bar graph is based on the flow cytometric analysis of KIR3DL1. This was the only receptor that was significantly $(P<0.05)$ increased in the MCFS group in comparison to the SCFS and non-fatigued controls. There was no significant difference between the SCFS group and the MCFS group. Asterisk denotes statistical significance where $P<0.05$ and data is represented as the mean \pm SEM

expression was significantly different between the MCFS group and the non-fatigued controls. There was a general trend of reduced receptor expression in the non-fatigued controls in comparison to the other two groups. However, most of these observations were not statistically significant (data not shown).

NK cytokines in severe CFS patients

In the present study, plasma cytokines were investigated in SCFS, MCFS and non-fatigued controls, where a significant increase in the plasma pro-inflammatory cytokines IFN- $\gamma$ and TNF- $\alpha$ were observed in the SCFS patients. Additionally, IL-4 was significantly increased in the SCFS group (Fig. 3). 

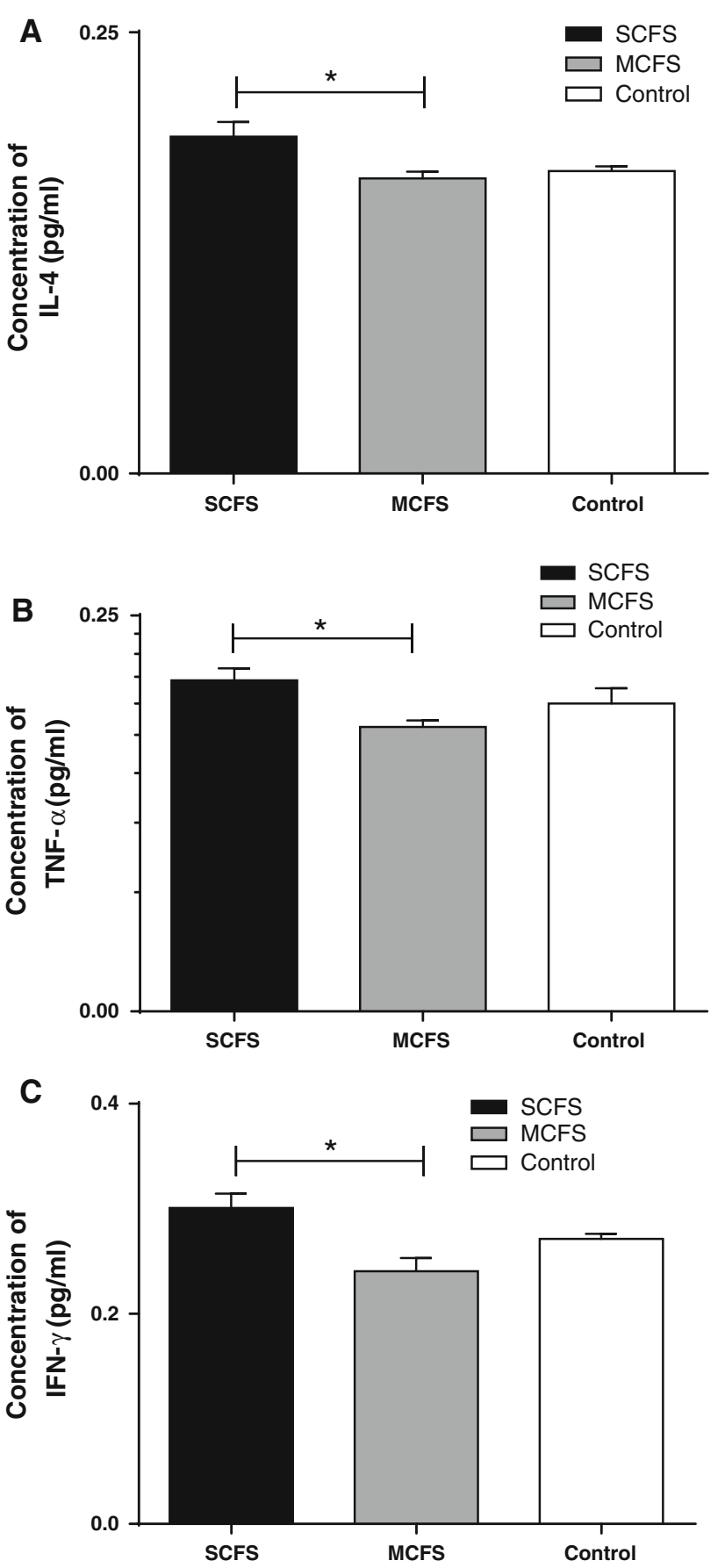

Fig. 3 Plasma Cytokines in SCFS, MCFS and a non-fatigued control group. The above bar graph is based on enzyme-linked immunosorbent assay (ELISA) assessments of seven plasma cytokines (IFN- $\gamma$, IL-1b/IL-1F2, IL-2, IL-4, IL-17, IL-6 and TNF- $\alpha$ ). IL-4 (a), TNF- $\alpha$ (b) and IFN- $\gamma(\mathbf{c})$ were significantly increased $(P<0.05)$ in the SCFS group in comparison to the MCFS and non-fatigued controls. Asterisk denotes statistical significance where $P<0.05$. Results are represented as the mean \pm SEM

\section{Conclusion}

This preliminary study is the first to examine and report immunological disparities in severely affected CFS patients characterised by significant decreases in NK lysis and increases in KIR3DL1, IL-4, TNF- $\alpha$ and IFN- $\gamma$.

The decreases in cytotoxic activity observed in the SCFS and MCFS group were consistent with previous CFS NK studies [34, 37, 69]. These NK disparities likely occur as a consequence of paucities in lytic proteins including perforin and granzymes and differential expression of their genes in some CFS patients $[37,85]$. These molecules are involved in the granule-dependent cytotoxic pathway. Perforin is a necessary component of this pathway as it facilitates the entry of the granzymes into the target cell. In the target cell, granzymes activate caspases, mitochondria-related apoptosis and reactive oxygen species, which induce apoptosis [123]. Importantly, mice deficient in perforin experience a substantial loss in cytotoxic activity. Reduced cytotoxic activity permits the recurrence and prolonged survival of various infections in the body possibly explaining the persistence of flu-like symptoms in the CFS patients. As correlations exist between cytotoxic activity and perforin in CFS patients, a similar incidence may present itself in SCFS patients perhaps at a more severe rate in comparison to the moderately affected CFS population. Nonetheless, further confirmatory studies are now required.

Significant increases in the expression of inhibitory KIRs may correspond to the reduced NK cell lysis [124]. Specifically, the significant increase in KIR3DL1 may be related to decreases in NK cell cytotoxicity of infectious cells with Class I HLA expression [101]. KIR3DL1 is a highly polymorphic inhibitory NK receptor and polymorphisms in its gene results in the generation of eight different KIR3DL1 allotypes that may be classified as having high, intermediate or no surface expression with similar affinity to bind antigens [102, 104, 105]. It associates with antigens expressing HLA-B and having Bw4 specificity [125]. Variations in the allotypes determine the response of the KIR3DL1 to pathogens at the cell surface [104]. For example expression of an inactivated KIRD3DL1 phenotype at the cell surface maybe subverted by ligands from viral pathogens and this may be related to certain disease presentations [126]. Similarly, polymorphisms within the HLA-Bw4 may undermine recognition by KIR3DL1 [127]. Increases in KIR3DL1 have been associated with diseases such as HIV and spondyloarthritis [66, 128]. KIR genes have previously been investigated in CFS patients where frequency of KIR3DS1 was significantly elevated in the CFS patients in comparison to the non-CFS group [65]. Similarly, the incidence of KIR3DL1 and KIR3DS1 without HLA-ligand and HLA Ile80, respectively, was higher among the CFS patients [65]. KIR3DL1 and KIR3DS1 are encoded by the same gene [109], hence, these observations implicate possible compromises to the genetic framework that confers atypical properties on these receptors and their allotypes inadvertently compromising cytotoxic activity. 
The increase in IFN- $\gamma$ did not correlate with an increase in cytotoxic activity as cytotoxicity was reduced in the CFS patients thus indicating that other cell types or cytokines such as TNF- $\alpha$ may have contributed to the overall increase in plasma IFN- $\gamma$ levels. The results on the cytokine studies further highlight profound compromises in the immune function of SCFS patients in comparison to the MCFS patients. IFN- $\gamma$ and TNF- $\alpha$ activate macrophages and $\mathrm{CD}^{+} \mathrm{T}$ cells and provoke $\mathrm{T}$ helper 1-related immune responses [129]. Persistent $T$ cell and macrophage activation, decreased NK activity and impaired perforin function is a hallmark of hemophagocytic lymphohistiocytosis [130]. Hence, atypical immune activation may exist among SCFS patients. Perhaps, cell-specific cytokine assessments may provide superior in-depth analysis of cytokines in CFS patients. Although, we have attempted to provide and highlight cytokines in plasma this may still not be representative of the cytokine profile in CFS patients as the source of most of these cytokines were not examined in this study and thus remains unknown. Nonetheless, this is the first study to report on cytokines in SCFS patients and may serve as a platform for further studies.

Contrary to previous studies, the present study did not demonstrate any significant reductions or changes in NK phenotypes. CFS is a heterogeneous disease and different subgroups of CFS patients may potentially express different distributions in immune cell phenotypes [55]. Incidentally, we have previously shown that alterations in NK phenotypes are not consistent overtime but fluctuate and are therefore poor indicators of immune function in CFS patients [31]. Reduced NK lysis with concomitant increases in KIR3DL1 and cytotoxic-related cytokines is suggestive of impairments in the NK cell cytotoxic pathways, in particular, the granule-dependent and -independent pathways. Further studies are now required to elucidate the mechanisms of these pathways in the CFS patients with varying degrees of symptom severity. Importantly, KIR receptors may be important biomarkers for the diagnosis of CFS following thorough validatory studies to determine their use in CFS diagnosis.

Conflict of interest E.W. Brenu, S.L. Hardcastle, G.M. Atkinson, Mieke L. van Driel, Sanne Kreijkamp-Kaspers, K.J. Ashton, D.R. Staines, S.M. Marshall-Gradisnik declare that they have no conflict of interest.

Informed consent All procedures followed were in accordance with the ethical standards of the responsible committee on human experimentation (institutional and national) and with the Helsinki Declaration of 1975, as revised in 2005. Informed consent was obtained from all patients for being included in the study.

Animal studies No animal studies were carried out by the authors for this article.

\section{References}

1. Galy A, Travis M, Cen D, Chen B (1995) Human T, B, natural killer, and dendritic cells arise from a common bone marrow progenitor cell subset. Immunity 3(4):459-473

2. Brennan FM, McInnes IB (2008) Evidence that cytokines play a role in rheumatoid arthritis. J Clin Investig 118(11):3537-3545. doi:10.1172/JCI36389

3. Barnes PJ (2008) The cytokine network in asthma and chronic obstructive pulmonary disease. J Clin Investig 118(11):3546-3556. doi:10.1172/JCI36130

4. Codarri L, Fontana A, Becher B (2010) Cytokine networks in multiple sclerosis: lost in translation. Curr Opin Neurol 23(3): 205-211. doi:10.1097/WCO.0b013e3283391feb

5. Steinman L (2008) Nuanced roles of cytokines in three major human brain disorders. J Clin Investig 118(11):3557-3563. doi: 10.1172/JCI36532

6. Miron N, Miron MM, Milea VG, Cristea V (2010) Proinflammatory cytokines: an insight into pancreatic oncogenesis. Roum Arch Microbiol Immunol 69(4):183-189

7. Grivennikov SI, Karin M (2011) Inflammatory cytokines in cancer: tumour necrosis factor and interleukin 6 take the stage. Ann Rheum Dis 70(Suppl 1):i104-i108. doi:10.1136/ard.2010. 140145

8. Skinnider BF, Mak TW (2002) The role of cytokines in classical Hodgkin lymphoma. Blood 99(12):4283-4297. doi:10.1182/ blood-2002-01-0099

9. Oppenheim J, Fujiwara H (1996) The role of cytokines in cancer. Cytokine Growth Factor Rev 7(3):279-288

10. Cooper MA, Fehniger TA, Turner SC, Chen KS, Ghaheri BA, Ghayur T, Carson WE, Caligiuri MA (2001) Human natural killer cells: a unique innate immunoregulatory role for the CD56(bright) subset. Blood 97(10):3146-3151

11. Caligiuri MA (2008) Human natural killer cells. Blood 112(3):461-469. doi:10.1182/blood-2007-09-077438

12. Vilches C, Parham P (2002) KIR: diverse, rapidly evolving receptors of innate and adaptive immunity. Annu Rev Immunol 20:217-251

13. Diaz-Pena R, Blanco-Gelaz MA, Lopez-Larrea C (2009) KIR genes and their role in spondyloarthropathies. Adv Exp Med Biol 649:286-299

14. Isakov N (1997) Immunoreceptor tyrosine-based activation motif (ITAM), a unique module linking antigen and $\mathrm{Fc}$ receptors to their signaling cascades. J Leukoc Biol 61(1):6-16

15. Brumbaugh KM, Binstadt BA, Billadeau DD, Schoon RA, Dick CJ, Ten RM, Leibson PJ (1997) Functional role for Syk tyrosine kinase in natural killer cell-mediated natural cytotoxicity. J Exp Med 186(12):1965-1974

16. Jiang K, Zhong B, Gilvary DL, Corliss BC, Hong-Geller E, Wei S, Djeu JY (2000) Pivotal role of phosphoinositide-3 kinase in regulation of cytotoxicity in natural killer cells. Nat Immunol 1(5):419-425. doi:10.1038/80859

17. Jiang K, Zhong B, Gilvary DL, Corliss BC, Vivier E, HongGeller E, Wei S, Djeu JY (2002) Syk regulation of phosphoinositide 3-kinase-dependent NK cell function. J Immunol 168(7): 3155-3164

18. Bryceson YT, March ME, Ljunggren HG, Long EO (2006) Synergy among receptors on resting NK cells for the activation of natural cytotoxicity and cytokine secretion. Blood 107(1): 159-166. doi:10.1182/blood-2005-04-1351

19. Zompi S, Hamerman JA, Ogasawara K, Schweighoffer E, Tybulewicz VL, Di Santo JP, Lanier LL, Colucci F (2003) NKG2D triggers cytotoxicity in mouse NK cells lacking DAP12 or Syk family kinases. Nat Immunol 4(6):565-572. doi:10.1038/ni930 
20. Raulet DH (2006) Missing self recognition and self tolerance of natural killer (NK) cells. Semin Immunol 18(3):145-150. doi: 10.1016/j.smim.2006.03.003

21. Voskoboinik I, Smyth MJ, Trapani JA (2006) Perforin-mediated target-cell death and immune homeostasis. Nat Rev Immunol 6(12):940-952. doi:10.1038/nri1983

22. Cullen SP, Martin SJ (2008) Mechanisms of granule-dependent killing. Cell Death Differ 15(2):251-262. doi:10.1038/sj.cdd. 4402244

23. Kono K, Takahashi A, Ichihara F, Sugai H, Fujii H, Matsumoto Y (2002) Impaired antibody-dependent cellular cytotoxicity mediated by herceptin in patients with gastric cancer. Cancer Res 62(20):5813-5817

24. Watanabe M, Kono K, Kawaguchi Y, Mizukami Y, Mimura K, Maruyama T, Izawa S, Fujii H (2010) NK cell dysfunction with down-regulated CD16 and up-regulated CD56 molecules in patients with esophageal squamous cell carcinoma. Dis Esophagus 23(8):675-681

25. Stratov I, Chung A, Kent SJ (2008) Robust NK cell-mediated human immunodeficiency virus (HIV)-specific antibody-dependent responses in HIV-infected subjects. J Virol 82(11): 5450-5459

26. Chung AW, Isitman G, Navis M, Kramski M, Center RJ, Kent SJ, Stratov I (2011) Immune escape from HIV-specific antibodydependent cellular cytotoxicity (ADCC) pressure. Proc Natl Acad Sci USA 108(18):7505-7510

27. Triulzi C, Vertuani S, Curcio C, Antognoli A, Seibt J, Akusjarvi G, Wei WZ, Cavallo F, Kiessling R (2010) Antibody-dependent natural killer cell-mediated cytotoxicity engendered by a kinaseinactive human HER2 adenovirus-based vaccination mediates resistance to breast tumors. Cancer Res 70(19):7431-7441. doi: 10.1158/0008-5472.CAN-10-0493

28. Wallin RP, Screpanti V, Michaelsson J, Grandien A, Ljunggren HG (2003) Regulation of perforin-independent NK cell-mediated cytotoxicity. Eur J Immunol 33(10):2727-2735. doi: 10.1002/eji.200324070

29. Ochi M, Ohdan H, Mitsuta H, Onoe T, Tokita D, Hara H, Ishiyama K, Zhou W, Tanaka Y, Asahara T (2004) Liver NK cells expressing TRAIL are toxic against self hepatocytes in mice. Hepatology 39(5):1321-1331. doi:10.1002/hep.20204

30. Screpanti V, Wallin RP, Grandien A, Ljunggren HG (2005) Impact of FASL-induced apoptosis in the elimination of tumor cells by NK cells. Mol Immunol 42(4):495-499. doi:10.1016/ j.molimm.2004.07.033

31. Brenu EW, van Driel ML, Staines DR, Ashton KJ, Hardcastle SL, Keane J, Tajouri L, Peterson D, Ramos SB, Marshall-Gradisnik SM (2012) Longitudinal investigation of natural killer cells and cytokines in chronic fatigue syndrome/myalgic encephalomyelitis. J Transl Med 10:88. doi:10.1186/14795876-10-88

32. Brenu EW, van Driel ML, Staines DR, Ashton KJ, Ramos SB, Keane J, Klimas NG, Marshall-Gradisnik SM (2011) Immunological abnormalities as potential biomarkers in chronic fatigue syndrome/myalgic encephalomyelitis. J Transl Med 9:81. doi: 10.1186/1479-5876-9-81

33. Fletcher MA, Zeng XR, Maher K, Levis S, Hurwitz B, Antoni M, Broderick G, Klimas NG (2010) Biomarkers in chronic fatigue syndrome: evaluation of natural killer cell function and dipeptidyl peptidase IV/CD26. PLoS ONE 5(5):e10817. doi: 10.1371/journal.pone.0010817

34. Brenu EW, Staines DR, Baskurt OK, Ashton KJ, Ramos SB, Christy RM, Marshall-Gradisnik SM (2010) Immune and hemorheological changes in chronic fatigue syndrome. J Transl Med 8:1. doi:10.1186/1479-5876-8-1

35. Mihaylova I, DeRuyter M, Rummens JL, Bosmans E, Maes M (2007) Decreased expression of CD69 in chronic fatigue syndrome in relation to inflammatory markers: evidence for a severe disorder in the early activation of $\mathrm{T}$ lymphocytes and natural killer cells. Neuro Endocrinol Lett 28(4):477-483

36. Siegel SD, Antoni MH, Fletcher MA, Maher K, Segota MC, Klimas N (2006) Impaired natural immunity, cognitive dysfunction, and physical symptoms in patients with chronic fatigue syndrome: preliminary evidence for a subgroup? J Psychosom Res 60(6):559-566. doi:10.1016/j.jpsychores.2006.03.001

37. Maher KJ, Klimas NG, Fletcher MA (2005) Chronic fatigue syndrome is associated with diminished intracellular perforin. Clin Exp Immunol 142(3):505-511. doi:10.1111/j.1365-2249. 2005.02935.x

38. Bansal AS, Bradley AS, Bishop KN, Kiani-Alikhan S, Ford B (2012) Chronic fatigue syndrome, the immune system and viral infection. Brain Behav Immun 26(1):24-31. doi:10.1016/j.bbi. 2011.06.016

39. Lieberman J, Fan Z (2003) Nuclear war: the granzyme A-bomb. Curr Opin Immunol 15(5):553-559

40. Ashton-Rickardt PG (2005) The granule pathway of programmed cell death. Crit Rev Immunol 25(3):161-182. doi: 2a1e865d14be9dc2,1831b39d0d3647ea [pii]

41. Bovenschen N, Quadir R, van den Berg AL, Brenkman AB, Vandenberghe I, Devreese B, Joore J, Kummer JA (2009) Granzyme K displays highly restricted substrate specificity that only partially overlaps with granzyme A. Journal Biol Chem 284(6):3504-3512. doi:10.1074/jbc.M806716200

42. Sutton VR, Wowk ME, Cancilla M, Trapani JA (2003) Caspase activation by granzyme B is indirect, and caspase autoprocessing requires the release of proapoptotic mitochondrial factors. Immunity 18(3):319-329. doi: S1074761303000505 [pii]

43. Heibein JA, Goping IS, Barry M, Pinkoski MJ, Shore GC, Green DR, Bleackley RC (2000) Granzyme B-mediated cytochrome c release is regulated by the Bcl-2 family members bid and Bax. J Exp Med 192(10):1391-1402

44. Lieberman J (2003) The ABCs of granule-mediated cytotoxicity: new weapons in the arsenal. Nat Rev Immunol 3(5):361-370. doi:10.1038/nri1083

45. Baran K, Dunstone M, Chia J, Ciccone A, Browne KA, Clarke CJ, Lukoyanova N, Saibil H, Whisstock JC, Voskoboinik I, Trapani JA (2009) The molecular basis for perforin oligomerization and transmembrane pore assembly. Immunity 30(5): 684-695. doi:10.1016/j.immuni.2009.03.016

46. Law RH, Lukoyanova N, Voskoboinik I, Caradoc-Davies TT, Baran K, Dunstone MA, D'Angelo ME, Orlova EV, Coulibaly F, Verschoor S, Browne KA, Ciccone A, Kuiper MJ, Bird PI, Trapani JA, Saibil HR, Whisstock JC (2010) The structural basis for membrane binding and pore formation by lymphocyte perforin. Nature 468(7322):447-451. doi:10.1038/nature09518

47. Cleare AJ (2003) The neuroendocrinology of chronic fatigue syndrome. Endocr Rev 24(2):236-252

48. Di Giorgio A, Hudson M, Jerjes W, Cleare AJ (2005) 24-hour pituitary and adrenal hormone profiles in chronic fatigue syndrome. Psychosom Med 67(3):433-440. doi:10.1097/01.psy. 0000161206.55324.8a

49. Fulle S, Belia S, Vecchiet J, Morabito C, Vecchiet L, Fano G (2003) Modification of the functional capacity of sarcoplasmic reticulum membranes in patients suffering from chronic fatigue syndrome. Neuromuscul Disord NMD 13(6):479-484

50. Goertzel BN, Pennachin C, de Souza Coelho L, Gurbaxani B, Maloney EM, Jones JF (2006) Combinations of single nucleotide polymorphisms in neuroendocrine effector and receptor genes predict chronic fatigue syndrome. Pharmacogenomics 7(3):475-483. doi:10.2217/14622416.7.3.475

51. Klimas NG, Koneru AO (2007) Chronic fatigue syndrome: inflammation, immune function, and neuroendocrine interactions. Curr Rheumatol Rep 9(6):482-487 
52. Lange G, DeLuca J, Maldjian JA, Lee H, Tiersky LA, Natelson BH (1999) Brain MRI abnormalities exist in a subset of patients with chronic fatigue syndrome. J Neurol Sci 171(1):3-7

53. Maes M, Mihaylova I, De Ruyter M (2006) Lower serum zinc in chronic fatigue syndrome (CFS): relationships to immune dysfunctions and relevance for the oxidative stress status in CFS. J Affect Disord 90(2-3):141-147. doi:10.1016/j.jad.2005.11.002

54. Maes M, Mihaylova I, Leunis JC (2006) Chronic fatigue syndrome is accompanied by an IgM-related immune response directed against neopitopes formed by oxidative or nitrosative damage to lipids and proteins. Neuro Endocrinol Lett 27(5): 615-621

55. Wilson A, Hickie I, Hadzi-Pavlovic D, Wakefield D, Parker G, Straus SE, Dale J, McCluskey D, Hinds G, Brickman A, Goldenberg D, Demitrack M, Blakely T, Wessely S, Sharpe M, Lloyd A (2001) What is chronic fatigue syndrome? Heterogeneity within an international multicentre study. Aust NZ J Psychiatry 35(4):520-527

56. Shepherd C (1992) Chronic fatigue syndrome: a joint paediatricpsychiatric approach. Arch Dis Child 67(11):1410

57. Nijhof SL, Maijer K, Bleijenberg G, Uiterwaal CS, Kimpen JL, van de Putte EM (2011) Adolescent chronic fatigue syndrome: prevalence, incidence, and morbidity. Pediatrics 127(5):e1169e1175. doi:10.1542/peds.2010-1147

58. Capelli E, Zola R, Lorusso L, Venturini L, Sardi F, Ricevuti G (2010) Chronic fatigue syndrome/myalgic encephalomyelitis: an update. Int J Immunopathol Pharmacol 23(4):981-989

59. Carruthers BM, van de Sande MI, De Meirleir KL, Klimas NG, Broderick G, Mitchell T, Staines D, Powles ACP, Speight N, Vallings R, Bateman L, Baumgarten-Austrheim B, Bell DS, Carlo-Stella N, Chia J, Darragh A, Jo D, Lewis D, Light AR, Marshall-Gradisbik S, Mena I, Mikovits JA, Miwa K, Murovska M, Pall ML, Stevens S (2011) Myalgic encephalomyelitis: International Consensus Criteria. J Intern Med 270(4):327-338. doi: 10.1111/j.1365 2796.2011.02428.x

60. Fukuda K, Straus SE, Hickie I, Sharpe MC, Dobbins JG, Komaroff A (1994) The chronic fatigue syndrome: a comprehensive approach to its definition and study. International Chronic Fatigue Syndrome Study Group. Ann Intern Med 121(12): 953-959

61. Ogawa M, Nishiura T, Yoshimura M, Horikawa Y, Yoshida H, Okajima Y, Matsumura I, Ishikawa J, Nakao H, Tomiyama Y, Kanayama Y, Kanakura Y, Matsuzawa Y (1998) Decreased nitric oxide-mediated natural killer cell activation in chronic fatigue syndrome. Eur J Clin Invest 28(11):937-943

62. Whiteside TL, Friberg D (1998) Natural killer cells and natural killer cell activity in chronic fatigue syndrome. Am J Med 105(3A):27S-34S

63. Levine PH, Whiteside TL, Friberg D, Bryant J, Colclough G, Herberman RB (1998) Dysfunction of natural killer activity in a family with chronic fatigue syndrome. Clin Immunol Immunopathol 88(1):96-104

64. Ojo-Amaize EA, Conley EJ, Peter JB (1994) Decreased natural killer cell activity is associated with severity of chronic fatigue immune dysfunction syndrome. Clin Infect Dis 18(Suppl 1):S157-S159

65. Pasi A, Bozzini S, Carlo-Stella N, Martinetti M, Bombardieri S, De Silvestri A, Salvaneschi L, Cuccia M (2011) Excess of activating killer cell immunoglobulinlike receptors and lack of HLA-Bw4 ligands: a twoedged weapon in chronic fatigue syndrome. Mol Med Rep 4(3):535-540. doi:10.3892/mmr.2011.447

66. Martin MP, Gao X, Lee JH, Nelson GW, Detels R, Goedert JJ, Buchbinder S, Hoots K, Vlahov D, Trowsdale J, Wilson M, O'Brien SJ, Carrington M (2002) Epistatic interaction between KIR3DS1 and HLA-B delays the progression to AIDS. Nat Genet 31(4):429-434. doi:10.1038/ng934
67. Jennes W, Verheyden S, Demanet C, Adje-Toure CA, Vuylsteke B, Nkengasong JN, Kestens L (2006) Cutting edge: resistance to HIV-1 infection among African female sex workers is associated with inhibitory KIR in the absence of their HLA ligands. J Immunol 177(10):6588-6592

68. Uhrberg M (2005) The KIR gene family: life in the fast lane of evolution. Eur J Immunol 35(1):10-15. doi:10.1002/eji. 200425743

69. Klimas NG, Salvato FR, Morgan R, Fletcher MA (1990) Immunologic abnormalities in chronic fatigue syndrome. J Clin Microbiol 28(6):1403-1410

70. Tirelli U, Marotta G, Improta S, Pinto A (1994) Immunological abnormalities in patients with chronic fatigue syndrome. Scand J Immunol 40(6):601-608

71. Thoren FB, Romero AI, Hermodsson S, Hellstrand K (2007) The CD16-/CD56bright subset of NK cells is resistant to oxidant-induced cell death. J Immunol 179(2):781-785

72. Harlin H, Hanson M, Johansson CC, Sakurai D, Poschke I, Norell H, Malmberg KJ, Kiessling R (2007) The CD16CD56(bright) NK cell subset is resistant to reactive oxygen species produced by activated granulocytes and has higher antioxidative capacity than the CD16 + CD56(dim) subset. J Immunol 179(7):4513-4519

73. Martin-Fontecha A, Thomsen LL, Brett S, Gerard C, Lipp M, Lanzavecchia A, Sallusto F (2004) Induced recruitment of NK cells to lymph nodes provides IFN-gamma for $\mathrm{T}(\mathrm{H}) 1$ priming. Nat Immunol 5(12):1260-1265. doi:10.1038/ni1138

74. Campbell JJ, Qin S, Unutmaz D, Soler D, Murphy KE, Hodge MR, Wu L, Butcher EC (2001) Unique subpopulations of CD56 + NK and NK-T peripheral blood lymphocytes identified by chemokine receptor expression repertoire. J Immunol 166(11):6477-6482

75. Robinson E, Keystone EC, Schall TJ, Gillett N, Fish EN (1995) Chemokine expression in rheumatoid arthritis (RA): evidence of RANTES and macrophage inflammatory protein (MIP)-1 beta production by synovial T cells. Clin Exp Immunol 101(3): 398-407

76. Dalbeth N, Gundle R, Davies RJ, Lee YC, McMichael AJ, Callan MF (2004) CD56bright NK cells are enriched at inflammatory sites and can engage with monocytes in a reciprocal program of activation. J Immunol 173(10):6418-6426

77. Wulff S, Pries R, Borngen K, Trenkle T, Wollenberg B (2009) Decreased levels of circulating regulatory NK cells in patients with head and neck cancer throughout all tumor stages. Anticancer Res 29(8):3053-3057

78. Mavilio D, Lombardo G, Benjamin J, Kim D, Follman D, Marcenaro E, O'Shea MA, Kinter A, Kovacs C, Moretta A, Fauci AS (2005) Characterization of CD56-/CD16+ natural killer (NK) cells: a highly dysfunctional NK subset expanded in HIV-infected viremic individuals. Proc Natl Acad Sci USA 102(8):2886-2891. doi:10.1073/pnas.0409872102

79. Robertson MJ, Schacterle RS, Mackin GA, Wilson SN, Bloomingdale KL, Ritz J, Komaroff AL (2005) Lymphocyte subset differences in patients with chronic fatigue syndrome, multiple sclerosis and major depression. Clin Exp Immunol 141(2):326-332. doi:10.1111/j.1365-2249.2005.02833.x

80. See DM, Cimoch P, Chou S, Chang J, Tilles J (1998) The in vitro immunomodulatory effects of glyconutrients on peripheral blood mononuclear cells of patients with chronic fatigue syndrome. Integr Physiol Behav Sci 33(3):280-287

81. Mawle AC, Nisenbaum R, Dobbins JG, Gary HE Jr, Stewart JA, Reyes M, Steele L, Schmid DS, Reeves WC (1997) Immune responses associated with chronic fatigue syndrome: a casecontrol study. J Infect Dis 175(1):136-141

82. Masuda A, Nozoe SI, Matsuyama T, Tanaka H (1994) Psychobehavioral and immunological characteristics of adult people 
with chronic fatigue and patients with chronic fatigue syndrome. Psychosom Med 56(6):512-518

83. Barker E, Fujimura SF, Fadem MB, Landay AL, Levy JA (1994) Immunologic abnormalities associated with chronic fatigue syndrome. Clin Infect Dis Off Publ Infect Dis Soc Am 18(Suppl 1):S136-S141

84. Bolitho P, Voskoboinik I, Trapani JA, Smyth MJ (2007) Apoptosis induced by the lymphocyte effector molecule perforin. Curr Opin Immunol 19(3):339-347. doi:10.1016/j.coi. 2007.04.007

85. Saiki T, Kawai T, Morita K, Ohta M, Saito T, Rokutan K, Ban N (2008) Identification of marker genes for differential diagnosis of chronic fatigue syndrome. Mol Med 14(9-10):599-607. doi: 10.2119/2007-00059.Saiki

86. Clark WR (1994) Immunology. The hole truth about perforin. Nature 369(6475):16-17. doi:10.1038/369016a0

87. Walsh CM, Matloubian M, Liu CC, Ueda R, Kurahara CG, Christensen JL, Huang MT, Young JD, Ahmed R, Clark WR (1994) Immune function in mice lacking the perforin gene. Proc Natl Acad Sci USA 91(23):10854-10858

88. Freud AG, Caligiuri MA (2006) Human natural killer cell development. Immunol Rev 214:56-72. doi:10.1111/j.1600065X.2006.00451.x

89. Salcedo TW, Azzoni L, Wolf SF, Perussia B (1993) Modulation of perforin and granzyme messenger RNA expression in human natural killer cells. J Immunol 151(5):2511-2520

90. Brady J, Hayakawa Y, Smyth MJ, Nutt SL (2004) IL-21 induces the functional maturation of murine NK cells. J Immunol 172(4):2048-2058

91. Fletcher MA, Zeng XR, Barnes Z, Levis S, Klimas NG (2009) Plasma cytokines in women with chronic fatigue syndrome. J Transl Med 7:96. doi:10.1186/1479-5876-7-96

92. Broderick G, Katz BZ, Fernandes H, Fletcher MA, Klimas NG, Smith FA, O'Gorman MR, Vernon SD, Taylor R (2012) Cytokine expression profiles of immune imbalance in post-mononucleosis chronic fatigue. J Transl Med 10(1):191. doi: 10.1186/1479-5876-10-191

93. Bossi G, Griffiths GM (2005) CTL secretory lysosomes: biogenesis and secretion of a harmful organelle. Semin Immunol 17(1):87-94. doi:10.1016/j.smim.2004.09.007

94. Kam CM, Hudig D, Powers JC (2000) Granzymes (lymphocyte serine proteases): characterization with natural and synthetic substrates and inhibitors. Biochim Biophys Acta 1477(1-2): 307-323

95. Tang H, Li C, Wang L, Zhang H, Fan Z (2012) Granzyme H of cytotoxic lymphocytes is required for clearance of the hepatitis $\mathrm{B}$ virus through cleavage of the hepatitis $\mathrm{B}$ virus $\mathrm{X}$ protein. J Immunol 188(2):824-831. doi:10.4049/jimmunol.1102205

96. Zhong C, Li C, Wang X, Toyoda T, Gao G, Fan Z (2012) Granzyme $\mathrm{K}$ inhibits replication of influenza virus through cleaving the nuclear transport complex importin alpha1/beta dimer of infected host cells. Cell Death Differ 19(5):882-890. doi:10.1038/cdd.2011.178

97. Ewen CL, Kane KP, Bleackley RC (2012) A quarter century of granzymes. Cell Death Differ 19(1):28-35. doi:10.1038/cdd. 2011.153

98. Tak PP, Spaeny-Dekking L, Kraan MC, Breedveld FC, Froelich CJ, Hack CE (1999) The levels of soluble granzyme A and B are elevated in plasma and synovial fluid of patients with rheumatoid arthritis (RA). Clin Exp Immunol 116(2):366-370

99. Morris G, Maes M (2012) Increased nuclear factor-kappaB and loss of p53 are key mechanisms in Myalgic Encephalomyelitis/ chronic fatigue syndrome (ME/CFS). Med Hypotheses 79(5):607-613. doi:10.1016/j.mehy.2012.07.034

100. Maes M, Twisk FN, Ringel K (2012) Inflammatory and cellmediated immune biomarkers in myalgic encephalomyelitis/ chronic fatigue syndrome and depression: inflammatory markers are higher in myalgic encephalomyelitis/chronic fatigue syndrome than in depression. Psychother Psychosom 81(5):286-295. doi:10.1159/000336803

101. Al Omar SY, Marshall E, Middleton D, Christmas SE (2011) Increased killer immunoglobulin-like receptor expression and functional defects in natural killer cells in lung cancer. Immunology 133(1):94-104. doi:10.1111/j.1365-2567.2011.03415.x

102. Uhrberg M, Valiante NM, Shum BP, Shilling HG, LienertWeidenbach K, Corliss B, Tyan D, Lanier LL, Parham P (1997) Human diversity in killer cell inhibitory receptor genes. Immunity 7(6):753-763

103. Valiante NM, Uhrberg M, Shilling HG, Lienert-Weidenbach K, Arnett KL, D'Andrea A, Phillips JH, Lanier LL, Parham P (1997) Functionally and structurally distinct NK cell receptor repertoires in the peripheral blood of two human donors. Immunity 7(6):739-751

104. Pando MJ, Gardiner CM, Gleimer M, McQueen KL, Parham P (2003) The protein made from a common allele of KIR3DL1 $(3 \mathrm{DL} 1 * 004)$ is poorly expressed at cell surfaces due to substitution at positions 86 in Ig domain 0 and 182 in Ig domain 1. J Immunol 171(12):6640-6649

105. Boulet S, Song R, Kamya P, Bruneau J, Shoukry NH, Tsoukas CM, Bernard NF (2010) HIV protective KIR3DL1 and HLA-B genotypes influence NK cell function following stimulation with HLA-devoid cells. J Immunol 184(4):2057-2064. doi:10.4049/ jimmunol.0902621

106. Lopez-Larrea C, Blanco-Gelaz MA, Torre-Alonso JC, Bruges Armas J, Suarez-Alvarez B, Pruneda L, Couto AR, Gonzalez S, Lopez-Vazquez A, Martinez-Borra J (2006) Contribution of KIR3DL1/3DS1 to ankylosing spondylitis in human leukocyte antigen-B27 Caucasian populations. Arthr Res Ther 8(4):R101. doi:10.1186/ar1988

107. Tomescu C, Duh FM, Hoh R, Viviani A, Harvill K, Martin MP, Carrington M, Deeks SG, Montaner LJ (2012) Impact of protective killer inhibitory receptor/human leukocyte antigen genotypes on natural killer cell and T-cell function in HIV-1infected controllers. Aids 26(15):1869-1878. doi:10.1097/QAD. 0b013e32835861b0

108. Jiang Y, He L, Chen H, Bice T, Zhang Z, Liu J, Ding H, Han X, Shang H (2011) Alteration of inhibitory and activating NK cell receptor expression on NK cells in HIV-infected Chinese. Cell Immunol 271(2):219-226. doi:10.1016/j.cellimm.2011.06.026

109. Morvan M, Willem C, Gagne K, Kerdudou N, David G, Sebille V, Follea G, Bignon JD, Retiere C (2009) Phenotypic and functional analyses of KIR3DL1+ and KIR3DS1+ NK cell subsets demonstrate differential regulation by Bw4 molecules and induced KIR3DS1 expression on stimulated NK cells. J Immunol 182(11):6727-6735. doi:10.4049/jimmunol.0900212

110. Kupfer DM, Burian D (2008) MicroRNA: the newest player in gene expression regulation. Aviat Space Environ Med 79(5):550-551

111. Sun Y, Wang M, Lin G, Sun S, Li X, Qi J, Li J (2012) Serum MicroRNA-155 as a potential biomarker to track disease in breast cancer. PLoS ONE 7(10):e47003. doi:10.1371/journal. pone. 0047003

112. Brenu EW, Ashton KJ, van Driel M, Staines DR, Peterson D, Atkinson GM, Marshall-Gradisnik SM (2012) Cytotoxic lymphocyte microRNAs as prospective biomarkers for Chronic Fatigue Syndrome/Myalgic Encephalomyelitis. J Affect Disord 141(2-3):261-269. doi:10.1016/j.jad.2012.03.037

113. Zhou B, Wang S, Mayr C, Bartel DP, Lodish HF (2007) miR150, a microRNA expressed in mature $\mathrm{B}$ and $\mathrm{T}$ cells, blocks early B cell development when expressed prematurely. Proc Natl Acad Sci USA 104(17):7080-7085. doi:10.1073/pnas. 0702409104 
114. Chan JA, Krichevsky AM, Kosik KS (2005) MicroRNA-21 is an antiapoptotic factor in human glioblastoma cells. Cancer Res 65(14):6029-6033. doi:10.1158/0008-5472.CAN-05-0137

115. Agirre X, Jimenez-Velasco A, San Jose-Eneriz E, Garate L, Bandres E, Cordeu L, Aparicio O, Saez B, Navarro G, VilasZornoza A, Perez-Roger I, Garcia-Foncillas J, Torres A, Heiniger A, Calasanz MJ, Fortes P, Roman-Gomez J, Prosper F (2008) Down-regulation of hsa-miR-10a in chronic myeloid leukemia CD34+ cells increases USF2-mediated cell growth. Mol Cancer Res MCR 6(12):1830-1840. doi:10.1158/15417786.MCR-08-0167

116. Fang Y, Shi C, Manduchi E, Civelek M, Davies PF (2010) MicroRNA-10a regulation of proinflammatory phenotype in athero-susceptible endothelium in vivo and in vitro. Proc Natl Acad Sci USA 107(30):13450-13455. doi:10.1073/pnas. 1002120107

117. Taganov KD, Boldin MP, Chang KJ, Baltimore D (2006) NFkappaB-dependent induction of microRNA miR-146, an inhibitor targeted to signaling proteins of innate immune responses. Proc Natl Acad Sci USA 103(33):12481-12486. doi:10.1073/ pnas.0605298103

118. Wang X, Tang S, Le SY, Lu R, Rader JS, Meyers C, Zheng ZM (2008) Aberrant expression of oncogenic and tumor-suppressive microRNAs in cervical cancer is required for cancer cell growth. PLoS ONE 3(7):e2557. doi:10.1371/journal.pone.0002557

119. Perry MM, Moschos SA, Williams AE, Shepherd NJ, LarnerSvensson HM, Lindsay MA (2008) Rapid changes in microRNA-146a expression negatively regulate the IL-1beta-induced inflammatory response in human lung alveolar epithelial cells. J Immunol 180(8):5689-5698

120. Sonkoly E, Pivarcsi A (2011) MicroRNAs in inflammation and response to injuries induced by environmental pollution. Mutat Res 717(1-2):46-53. doi:10.1016/j.mrfmmm.2011.02.002

121. Wu GQ, Zhao YM, Huang H, Lai XY (2011) Effects of blocking inhibitory KIR receptors on cytotoxic activity of human NK cells in vitro. Zhejiang Da Xue Xue Bao Yi Xue Ban 40(5): 475-481

122. Wiborg JF, van der Werf S, Prins JB, Bleijenberg G (2010) Being homebound with chronic fatigue syndrome: a multidimensional comparison with outpatients. Psychiatry Res 177(1-2):246-249. doi:10.1016/j.psychres.2010.02.010

123. Siegmund D, Wicovsky A, Schmitz I, Schulze-Osthoff K, Kreuz S, Leverkus M, Dittrich-Breiholz O, Kracht M, Wajant H (2005) Death receptor-induced signaling pathways are differentially regulated by gamma interferon upstream of caspase 8 processing. Mol Cell Biol 25(15):6363-6379. doi:10.1128/MCB.25. 15.6363-6379.2005

124. Khakoo SI, Thio CL, Martin MP, Brooks CR, Gao X, Astemborski J, Cheng J, Goedert JJ, Vlahov D, Hilgartner M, Cox S, Little AM, Alexander GJ, Cramp ME, O’Brien SJ, Rosenberg WM, Thomas DL, Carrington M (2004) HLA and NK cell inhibitory receptor genes in resolving hepatitis $\mathrm{C}$ virus infection. Science 305(5685):872-874. doi:10.1126/science.1097670

125. Stern M, Ruggeri L, Capanni M, Mancusi A, Velardi A (2008) Human leukocyte antigens A23, A24, and A32 but not A25 are ligands for KIR3DL1. Blood 112(3):708-710. doi:10.1182/ blood-2008-02-137521

126. Franceschelli S, Rosati A, Lerose R, De Nicola S, Turco MC, Pascale M (2008) Bag3 gene expression is regulated by heat shock factor 1. J Cell Physiol 215(3):575-577. doi:10.1002/ jcp. 21397

127. Thananchai H, Gillespie G, Martin MP, Bashirova A, Yawata N, Yawata M, Easterbrook P, McVicar DW, Maenaka K, Parham P, Carrington M, Dong T, Rowland-Jones S (2007) Cutting Edge: allele-specific and peptide-dependent interactions between KIR3DL1 and HLA-A and HLA-B. J Immunol 178(1):33-37

128. Scrivo R, Morrone S, Spadaro A, Santoni A, Valesini G (2011) Evaluation of degranulation and cytokine production in natural killer cells from spondyloarthritis patients at single-cell level. Cytom Part B Clin Cytom 80(1):22-27. doi:10.1002/cyto.b.20549

129. Castoldi L, Golim MA, Filho OG, Romagnoli GG, Ibanez OC, Kaneno R (2007) Enhanced natural killer activity and production of pro-inflammatory cytokines in mice selected for high acute inflammatory response (AIRmax). Immunology 120(3): 372-379. doi:10.1111/j.1365-2567.2006.02513.x

130. Lunemann A, Lunemann JD, Munz C (2009) Regulatory NKcell functions in inflammation and autoimmunity. Mol Med 15(9-10):352-358. doi:10.2119/molmed.2009.00035 